\title{
Localized Ventilation Method for Providing Clean Air to Hospitalized Patients
}

\author{
Lei Shu ${ }^{1}$, Mariya P. Bivolarova ${ }^{1 *}$, and Arsen K. Melikov ${ }^{1}$ \\ ${ }^{1}$ International Centre for Indoor Environment and Energy, Department of Civil Engineering, Technical University of Denmark, 2800 \\ Kgs. Lyngby, Denmark
}

\begin{abstract}
Three novel air terminal devices (ATDs) for localized ventilation were designed (ATD with perforated inner plate, ATD with honeycomb diffuser, and ATD with lobbed nozzle). The ability of the ATDs to provide clean air to the breathing zone of a person lying in a hospital bed was studied. Experiments were performed in a simulated full-scale hospital patient room. A thermal manikin was used to simulate a patient. The ATD was located above the head of manikin. Heated dummy simulated a doctor standing beside the bed. Tracer gas was used to simulate contaminated air exhaled by the doctor. The supply and the exhaust flow rates were controlled at $15.3 \mathrm{~L} / \mathrm{s}$ and $14.8 \mathrm{~L} / \mathrm{s}$, respectively. The supply air temperature and room temperature were kept at $23{ }^{\circ} \mathrm{C}$ and $25.3{ }^{\circ} \mathrm{C}$, respectively. Increase of the supply air speed resulted in a cleaner air supply to the breathing zone but also increased the risk of draught. The ATD with a lobbed jet nozzle was able to reduce contaminants by more than half in the breathing zone and to provide the lowest draught risk at the face. This ATD is a better solution to supply clean air in practice comparing to the other two ATDs.
\end{abstract}

\section{Introduction}

Ventilation targets to provide sufficient and clean air to occupants in buildings for breathing. Inhaled air quality is important for the healing of patients in hospitals. Appropriately designed ventilation strategy and air distribution pattern in hospital wards may reduce airborne transmission of infectious agents and minimize healthcare associated infections (HAIs) [1]. The coronavirus disease 2019 (COVID-19), which has the potential of airborne transmission [2], has had an enormous impact globally. During the pandemic period of COVID-19, numerous traditional infection prevention resources, such as traditional personal protective equipment (PPE), were adapted to protect people from the cross-infection of COVID-19. Because of the lack of medical resources, many conventional infection prevention duties were compromised leading to more cross-infection and HAIs that should have been prevented under normal circumstances (no pandemic) [3]. Ventilation is considered as an efficient method to reduce the airborne transmission of pathogens and make up for the shortage of other traditional infection prevention resources. In order to reduce the transmission of the COVID-19 pandemic, a substantial increase of the ventilation rate in buildings was recommended [4][5]. However, increasing ventilation rate will result in higher energy consumption and the risk of draught discomfort. Furthermore, ventilation systems in buildings are mainly designed for removing heat and pollution loads under normal conditions (no pandemic). The airhandling units, ducts, air supply, and exhaust terminal devices are dimensioned to be economic and energyefficient, thus only allowing limited increase in the ventilation rate. If ventilation systems are designed for the case of pandemic i.e., a large amount of outdoor air is available during the pandemic, they will not run economically under normal circumstances (no pandemic) with a considerably decreased supply airflow rate [6]. In addition, increasing ventilation rate may also cause complicated flow interactions and spread, leading to even higher exposure for the patients [7]. Hence, increasing ventilation rate is not always a feasible method to reduce airborne transmission in all conditions. Other ventilation strategies for efficient clean air supply are needed.

The ventilation often used of spaces (mainly based on mixing air distribution) supplies fresh air to the entire room. It is energy inefficient and hard to control the airflow distribution in the breathing zone [6]. It may not perform efficiently and economically when there is a pandemic. Localized ventilation with relatively less ventilated airflow rate may perform better for providing clean air for breathing. Three novel air terminal devices (ATDs) for localized ventilation were investigated in this study to find a more efficient way for reducing the risk of airborne infection comparing to the used at present ventilation.

\footnotetext{
* Corresponding author: mbiv@byg.dtu.dk
} 


\section{Full-scale experiments}

\subsection{Simulated patient room}

Full-scale experiments were conducted in a simulated general patient room. Figure 1 shows the fullscale room with a dimension of $4.7 \mathrm{~m} \times 4.7 \mathrm{~m} \times 2.6 \mathrm{~m}$ $(\mathrm{W} \times \mathrm{L} \times \mathrm{H})$. The room air was exhausted via a circular perforated exhaust diffuser with $\varnothing 160 \mathrm{~mm}$. The exhaust diffuser was located on the ceiling and its centre was at distances of $1.11 \mathrm{~m}$ from the back wall and $0.31 \mathrm{~m}$ from the right-side wall. Clean outdoor air was supplied to the room via one of the new ATDs designed to provide locally clean air to the patient's breathing zone. The centre of the air terminal devices was at distances of 1.11 $\mathrm{m}$ from the back wall and of $2.65 \mathrm{~m}$ from the right-side wall. It hung at $118 \mathrm{~cm}$ above the face of the full-sized thermal manikin (TM) that was used to simulate a patient lying in bed (Figure 1). The thermal manikin resembled the body of an average Scandinavian woman of height $1.7 \mathrm{~m}$ and consisted of 17 body segments. The heat loss $\left(\mathrm{W} / \mathrm{m}^{2}\right)$ and surface temperature of each body segment were controlled to maintain the surface temperature of the manikin's body equal to the skin temperature of an average person in a state of thermal neutrality. The manikin was dressed in short-sleeve pajama. A light-weight quilt was placed on top of the TM covering the manikin up to its neck. A heated dummy emitting $190 \mathrm{~W}$ of heat was used as a doctor standing next to the bed (Figure 1).

Nitrous oxide $\left(\mathrm{N}_{2} \mathrm{O}\right)$ tracer gas was used to simulate air contaminants generated from the "mouth" of the heated dummy. The concentration of the tracer gas was measured at the thermal manikin's mouth $(118 \mathrm{~cm}$ below the ATD inner plate), $40 \mathrm{~cm}$ above the TM mouth (78 cm below the ATD inner plate), in the local ATD, and in the exhaust diffuser. The tracer gas concentration was measured by a Multi-gas sampler and analyzer 1303 and 1312 INNOVA. Low velocity thermal anemometers with transducers HT 400 with omnidirectional velocity sensors were used to measure the speed, standard deviation, turbulence intensity, and draught rate of the air flow from the local ATD. These parameters were measured in several locations along and across the jet generated by the local ATD using a stand with four velocity transducers at distances of $10 \mathrm{~cm}, 18 \mathrm{~cm}, 73 \mathrm{~cm}$, and $98 \mathrm{~cm}$ below the ATD. In the horizontal direction, the transducers were placed at different distances from the centre of the ATD: 0, 6, 12, 16, 20, $24 \mathrm{~cm}$. Smoke visualizations were carried out to observe the distribution of pollutants exhaled by the doctor in the room. A vaporizing fog generator generated smoke and the smoke was released at the "mouth" of the heated dummy via a plastic tube. A black plate with a grid was placed as a background to make smoke movement more visible. During the experiments, the simulated patient room was kept at slightly over-pressure to avoid infiltration of tracer gas into the room. The supply and the exhaust flow rates were $15.3 \mathrm{~L} / \mathrm{s}$ and $14.8 \mathrm{~L} / \mathrm{s}$, respectively. The supply and exhaust flow rates were controlled by air flow sensors (MFS-C-080) (with maximum measurement error of $\pm 3 \%$ ). The supply air temperature was $23{ }^{\circ} \mathrm{C} \pm 0.1{ }^{\circ} \mathrm{C}$. The room air temperature was kept at $25.3^{\circ} \mathrm{C} \pm 0.2{ }^{\circ} \mathrm{C}$.

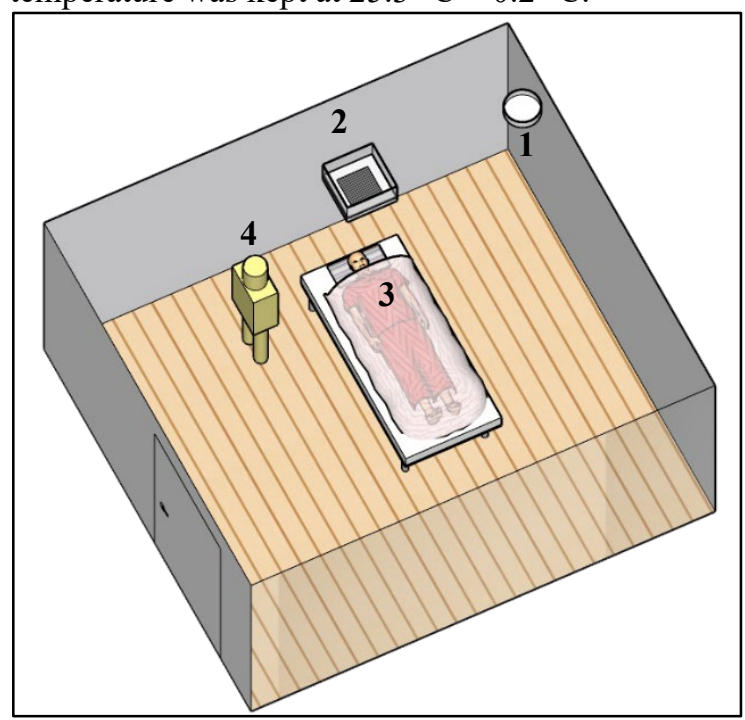

Figure 1. Experimental set-up of the patient room:1-exhaust diffuser, 2-supply local air terminal device (ATD), 3-thermal manikin as a patient, and 4-heated dummy as a doctor.

\subsection{Air supply terminal devices (ATDs)}

Three air supply terminal devices for localized ventilation were investigated. The outer dimensions of the ATDs were $0.41 \mathrm{~m} \times 0.41 \mathrm{~m} \times 0.25 \mathrm{~m}(\mathrm{~W} \times \mathrm{L} \times \mathrm{H})$. Their inner structures were different aiming to supply different air jets as described in the following subsections.

\subsubsection{ATD with perforated inner plate}

The ATD with a perforated inner plate consisted of 4 parts: a plastic box, a synthetic fibre filter with $10 \mathrm{~mm}$ thickness, a metal perforated plate (size: $0.24 \mathrm{~m} \times 0.24$ m) with $1 \mathrm{~mm}$ thickness, and a hollow plastic plate (Figure 2). The perforated metal plate had $5 \mathrm{~mm}$ holes with a distance of $0.5 \mathrm{~mm}$ between them. The synthetic fibre filter was placed on top of the holes of the plastic plate in order to assure uniform airflow distribution and to provide resistance for the air passing through the holes of the plate. This design of this ATD assured a coaxial rectangular jet.

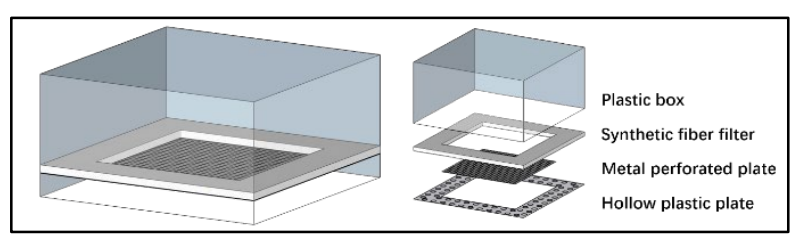

Figure 2. ATD with perforated inner plate.

\subsubsection{ATD with inner honeycomb diffuser}

The ATD with an inner honeycomb diffuser was comprised of 5 parts: a plastic box, a synthetic fibre filter with $10 \mathrm{~mm}$ thickness, a metal honeycomb with $30 \mathrm{~mm}$ 
thickness, a hollow plastic plate, and a synthetic fibre filter with $20 \mathrm{~mm}$ thickness (Figure 3). A metal honeycomb $(0.24 \mathrm{~m} \times 0.24 \mathrm{~m})$ was embedded in the middle of the plastic plate. The synthetic fibre filters were attached on both sides of the plastic plate to cover its holes. This design resulted in another type of coaxial rectangular jet.

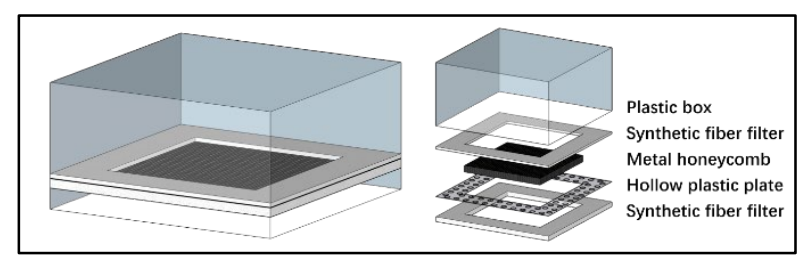

Figure 3. ATD with inner honeycomb diffuser.

\subsubsection{ATD with lobbed jet nozzle}

The ATD with a lobbed jet nozzle was composed of 3 parts: a plastic box, a synthetic fibre filter with $20 \mathrm{~mm}$ thickness and an inner plate having an opening shaped as a 6-edges lobbed star (Figure 4). The inner plate is made from poliestireno extruido (XPS) plate. A lobbed jet was assured in this design.

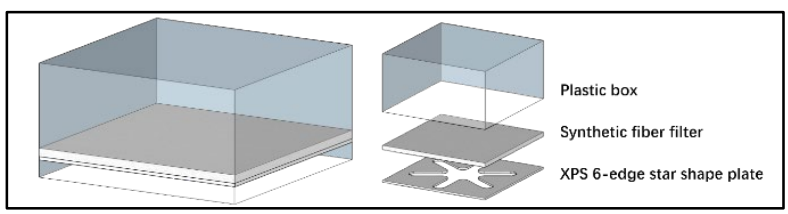

Figure 4. ATD with lobbed jet nozzle.

\section{Results}

\subsection{Inhaled air cleanness}

The clean air supply efficiency of new local ATDs was evaluated with regard to contaminants concentration measured at the TM mouth. The concentration of contaminants at the mouth was expressed in terms of their normalized values [8], defined as $\left(\mathrm{C}_{\mathrm{i}}-\mathrm{C}_{\mathrm{s}}\right) /\left(\mathrm{C}_{\text {exh }}-\mathrm{C}_{\mathrm{s}}\right)$, where $\mathrm{C}_{\mathrm{i}}, \mathrm{C}_{\mathrm{s}}, \mathrm{C}_{\text {exh }}$ are the contaminants concentration measured at the mouth, supply and exhaust air, respectively. The contaminants concentration $40 \mathrm{~cm}$ above the TM mouth was measured and expressed in the same way to investigate the contaminants concentration distribution. If the normalized value is lower than 1 , it means that the simulated contaminants at the measured point were lower than in the exhaust room air. Figure 5 shows the results of the normalized concentration obtained during the operation of each local ATD. The coaxial rectangular jet with the perforated plate provided about $28 \%$ clean air to the mouth of the thermal manikin. The performance of this design was not as good as the performance of the lobbed jet that provided about $53 \%$ clean air for breathing. A significant reduction (70\%) of exposure could be observed when using the coaxial rectangular jet with inner honeycomb plate. The efficiency of the ATD with inner honeycomb was the highest among the three ATDs in terms of inhaled air cleanness.

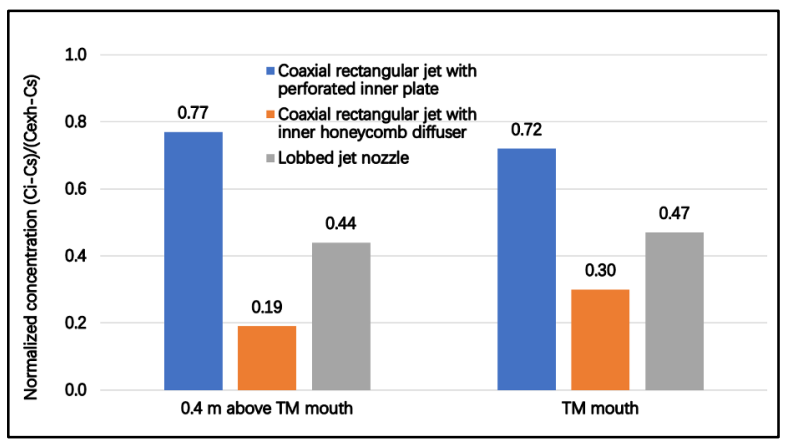

Figure 5. Normalized concentration distribution.

At the point $40 \mathrm{~cm}$ above the TM mouth, the normalized contaminants concentrations were $11 \%$ and $3 \%$ lower compared to the value at the TM mouth when using the ATDs with honeycomb plate and the lobbed jet nozzle, respectively. The normalized contaminants concentration at $40 \mathrm{~cm}$ above the TM mouth was $5 \%$ higher when using the ATD with the perforated metal inner plate. These results show that the distance between the local ATD and the patient is important for the entrainment of the air pollutants into the supply air jet. It can be expected that the efficiency of the ATDs will increase with decreasing the distance and vice versa.

\subsection{Draught discomfort}

Except for good indoor air quality, comfortable thermal environment in hospital wards is also beneficial for the recovery of patients [1]. In this study, thermal environment and draught rate (DR) were assessed. Because the quilt was covering the body of the TM and the head of TM faced the cool clean air supplied by the ATD, only dry heat loss of the TM head and the top of TM head were analyzed to evaluate the thermal discomfort.

Figure 6 shows the dry heat loss of the head and top of the head. The highest dry heat loss of the TM head occurred when the coaxial rectangular jet with honeycomb plate was used, about $22 \mathrm{~W} / \mathrm{m}^{2}$ much higher than the reference value obtained when the local ATD was OFF and the room was ventilated with mixing air distribution only at $15 \mathrm{~L} / \mathrm{s}$. The dry heat loss of the TM head when using lobbed jet and coaxial rectangular jet with a perforated plate were about 14 and $6 \mathrm{~W} / \mathrm{m}^{2}$ higher than the reference value, respectively. The dry heat loss of the top of the head raised about 11,10 , and $5 \mathrm{~W} / \mathrm{m}^{2}$ compared to the reference value when using coaxial rectangular jet with a perforated plate and with honeycomb diffuser and lobbed jet, respectively. 


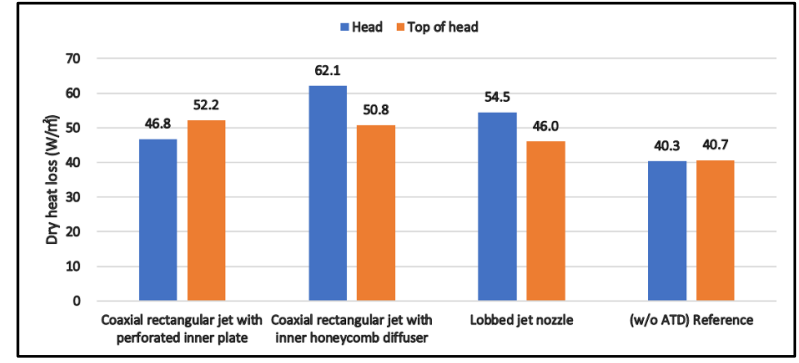

Figure 6. Dry heat loss.

Figure 7 shows the draught rate distribution across the vertical centreline of the ATDs. In Figure 7, on the $y$-axis are shown the four heights at which the draught rate was measured. At the point closest to the mouth of the TM (i.e., at the height of $98 \mathrm{~cm}$ below the ATD inner plate), the draught rate generated by the coaxial rectangular jet with inner honeycomb diffuser (40\%) were more than twice the draught rate generated by the lobbed jet $(20 \%)$ and the coaxial rectangular jet with perforated inner plate $(15 \%)$. This result supports the finding that the ATD with honeycomb plate provided the highest heat loss, i.e., the highest cooling effect to the head.

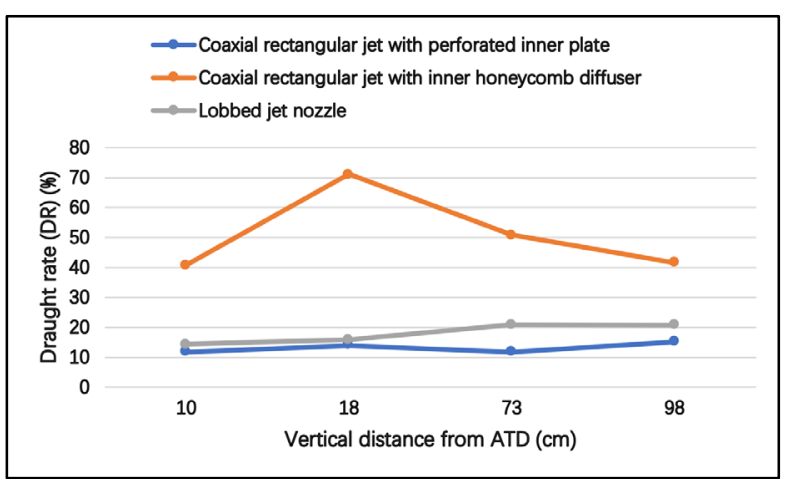

Figure 7. Draught rate (DR) distribution.

\subsection{Air speed profile}

Effects of different jets' air speed profile on their performances for providing clean air for breathing were investigated. Air speed distribution across the jet at different horizontal distances from the ATD centre was identified.

Figure 8 shows the air speed distribution in the coaxial rectangular jet generated by the ATD with perforated inner plate. The air speeds at different heights across the centreline of the jet at the four measured heights $(10,18,73$, and $98 \mathrm{~cm}$ below the ATD inner plate) were low, from $0.125 \mathrm{~m} / \mathrm{s}$ to $0.175 \mathrm{~m} / \mathrm{s}$.

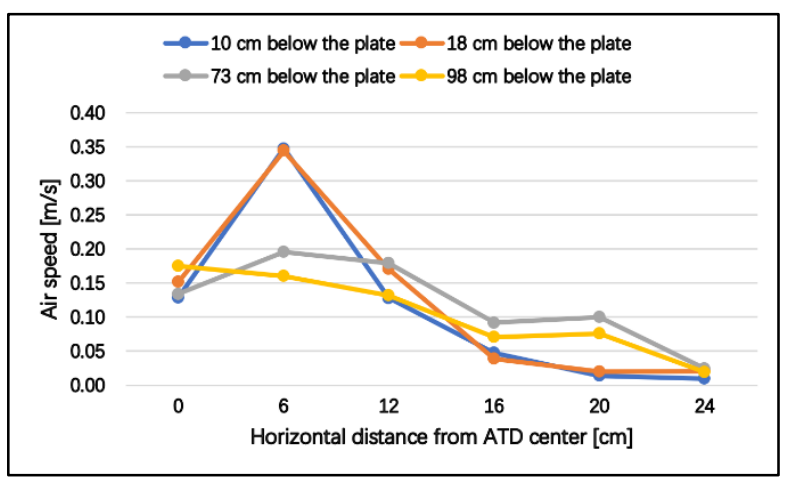

Figure 8. Air speed distribution in the coaxial rectangular jet with perforated inner plate.

Figure 9 shows the air speed distribution caused by the coaxial rectangular jet with a honeycomb diffuser. The air speeds at different heights at the vertical centreline were relatively high, from $0.45 \mathrm{~m} / \mathrm{s}$ to 0.75 $\mathrm{m} / \mathrm{s}$.

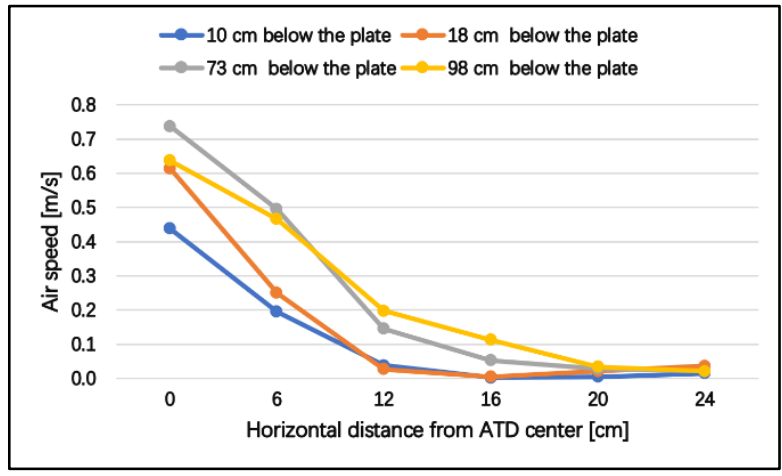

Figure 9. Air speed distribution in the coaxial rectangular jet with inner honeycomb diffuser.

Figure 10 shows the lobbed jet air speed distribution. The air speeds at different heights at the vertical centreline of the jet were moderate, from $0.25 \mathrm{~m} / \mathrm{s}$ to $0.35 \mathrm{~m} / \mathrm{s}$.

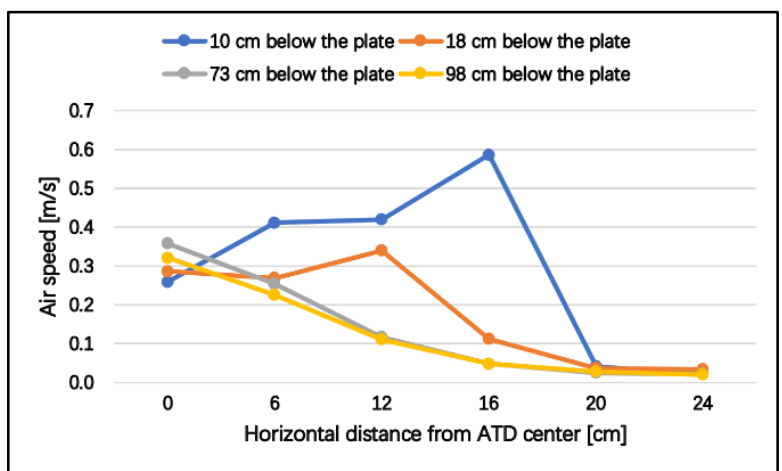

Figure 10. Air speed distribution in the lobbed jet.

For the three different jets, the shape of the air speed distribution profile from $73 \mathrm{~cm}$ to $98 \mathrm{~cm}$ below the ATD inner plate almost had the "bell shape" characteristic for fully developed free jets. Because of the difference in the structure of the three ATDs, the air speed distribution profiles close to the ATD (from $10 \mathrm{~cm}$ to 18 $\mathrm{cm}$ below the plate) were different. 


\subsection{Visualization}

The coaxial rectangular jet with perforated inner plate and inner honeycomb diffuser were visualized.

Figure 11 shows the visualization of the coaxial rectangular jet with perforated inner plate., It can be seen that one part of the smoke raised up due to the free convective flow around the dummy, entrained the supply jet and spread to the zone under the box diffuser. Another part of the smoke it spread vertically to the zone above the breathing zone of the thermal manikin.

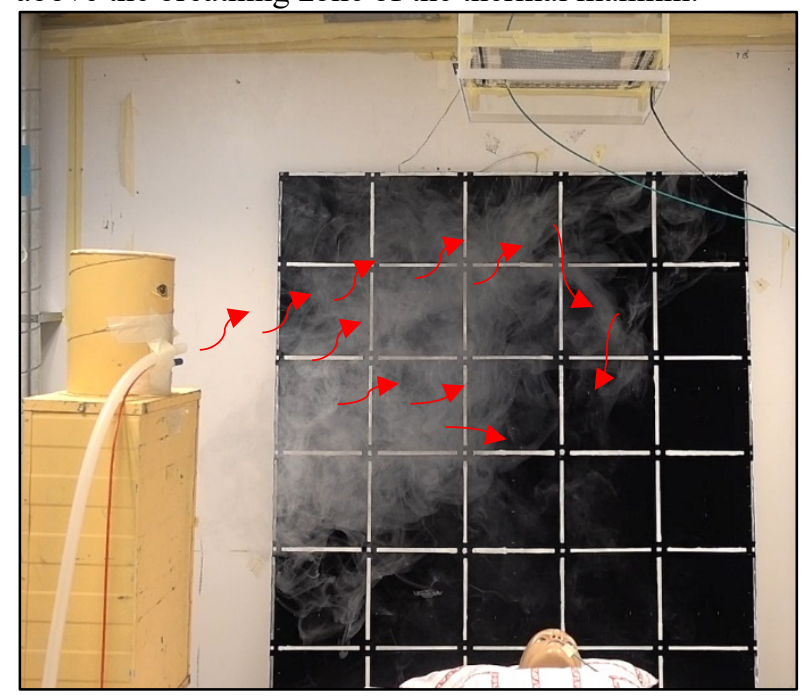

Figure 11. Smoke visualization of the coaxial rectangular jet with perforated inner plate.

Figure 12 shows the visualization of coaxial rectangular jet with inner honeycomb diffuser. It can be seen that the smoke does not disseminate horizontally above the TM mouth. This was because the velocity of the supply jet was high enough to prevent entrainment of most of the room air. Figure 12 shows that the smoke was pushed away downward to the left vertical side of the TM's head.

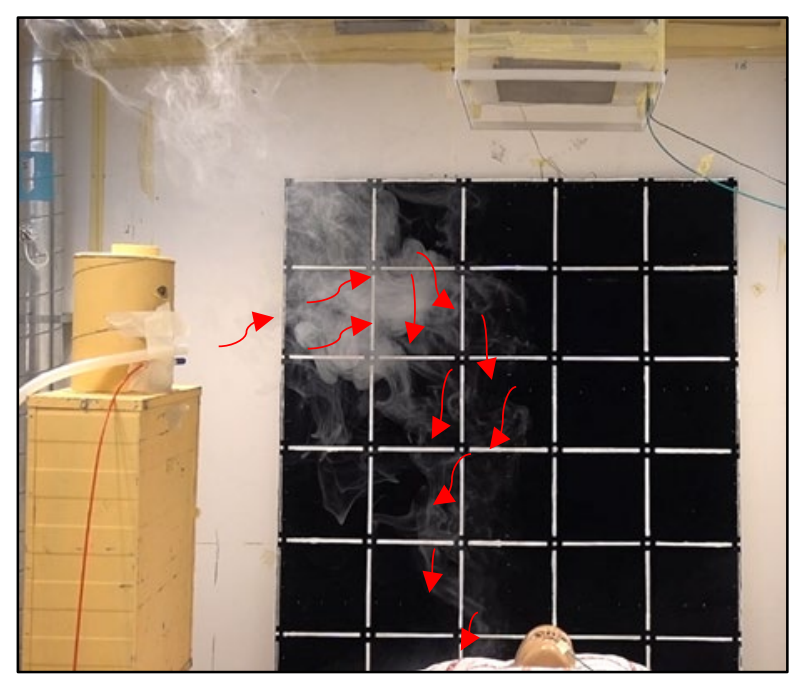

Figure 12. Smoke visualization of the coaxial rectangular jet with inner honeycomb diffuser.

\section{Discussion}

When comparing the air speed distribution at the centreline of the jets and the normalized contaminants concentration, it was found that higher air speed above the TM mouth (at the centreline of the jets) corresponded to lower contaminants concentration. This shows that the high downward air speed prevented entrainment of airborne contaminants. Results obtained with overhead mixing air distribution at $15.3 \mathrm{~L} / \mathrm{s}$ supply flow rate (not shown in this paper) reveal that the pollution concentration at the patient's mouth was reduced with only $10 \%$ compared to the coaxial rectangular jet with inner honeycomb diffuser (which provided $70 \%$ pollution reduction).

In the coaxial rectangular jet generated by the ATD with the perforated inner plate (Figure 8), the air speed from $73 \mathrm{~cm}$ to $98 \mathrm{~cm}$ below the ATD inner plate increased, while the other two jets' corresponding air speed decreased (Figure 9 and Figure 10). It can be seen in Figure 5, that the normalized contaminant concentration from $40 \mathrm{~cm}$ above the TM mouth to the TM mouth decreased when using the ATD with a perforated inner plate, while corresponding normalized contaminants concentration increased when using the other two ATDs. This also indicated that higher air speed led to lower airborne contaminants concentration for localized ventilation. However, higher air speed also increased the undesirable risk of draught. In order to reduce the expected draught discomfort, maybe the supply air temperature can be increased or the supply flow rate to be decreased. This, however, will have effects on the room air movement. If the flow supplied by the ATD is weak in order to avoid draught then the room air movement may push it away from the patient. So, careful design of both, local ventilation and background ventilation will be required. This will be studied in the future.

\section{Conclusions}

The ATD with coaxial rectangular jet with a honeycomb diffuser performs the best in providing clean air to the mouth of the patient in bed. Its high efficiency may result from downward airflow with high air speed, which prevents entrainment of airborne contaminants. However, this design may cause draught discomfort. In practice, implementing the ATD with a lobbed jet nozzle can be a better solution. This diffuser is able to reduce the contaminants by more than half in the breathing zone and also provides less draught close to the face. Experiments with human subjects need to be performed in order to identify the thermal comfort of people when using ATDs.

The velocity distribution across the flow supplied from the diffuser has a big influence on providing clean air to the breathing zone. More specifically, higher air speed may result in higher efficiency of air cleanness and higher discomfortable draught rate. A higher efficient clean air supply can be obtained by improving jets' airflow characteristics. Modifying the design of air 
terminal devices (ATDs), rather than increasing the airflow rate, may lead to desirable jets' air speed profile.

The simulated general patient room was kept at slightly over-pressure while airborne infection isolation rooms are designed under negative pressure [9]. The influences of the pressure difference need to be studied if the new localized method of ventilation is going to be applied in isolation rooms. Factors that may affect air speed of the jet, such as supply air volume and air temperature difference between supply air and indoor air, need further studies. The influences of the size of ATDs and the background ventilation influence on air supply efficiency are recommended to be studied. In addition, the ratio of the flows supplied from the outer jet and inner jet of the diffusers have not been controlled and need to be studied.

This research was funded by Region Sjaelland, Denmark as a part of the "Mental Shower" project.

\section{References}

[1] A. Shajahan, C. H. Culp, and B. Williamson, "Effects of indoor environmental parameters related to building heating, ventilation, and air conditioning systems on patients' medical outcomes: A review of scientific research on hospital buildings," Indoor Air, vol. 29, no. 2, pp. 161-176, 2019.

[2] L. Morawska and D. K. Milton, "It Is Time to Address Airborne Transmission of Coronavirus Disease 2019 (COVID-19)," Clin. Infect. Dis. an Off. Publ. Infect. Dis. Soc. Am., vol. 71, no. 9, pp. 2311-2313, 2020.

[3] M. P. Stevens, M. Doll, R. Pryor, E. Godbout, K. Cooper, and G. Bearman, "Impact of COVID-19 on traditional healthcare-associated infection prevention efforts," Infect. Control Hosp. Epidemiol., vol. 41, no. 8, pp. 946-947, 2020.

[4] “ASHRAE Position Document on Infectious Aerosols," Ashrae, 2020.

[5] "How to Operate HVAC and Other Building Service Systems to Prevent the Spread of the Coronavirus (SARS-CoV-2) Disease (COVID19) in Workplaces," REHVA COVID-19 Guidance Document, 2020.

[6] A. K. Melikov, "COVID-19: Reduction of airborne transmission needs paradigm shift in ventilation," Build. Environ., vol. 186, 2020.

[7] N. Kehayova, Z. D. Bolashikov, A. K. Melikov, "Subjective Evaluation of the Microenvironment Generated by a Hospital Bed with Localized Ventilation System,", 2016.

[8] R. Cermak, A. K. Melikov, L. Forejt, and O. Kovar, "Performance of Personalized Ventilation in Conjunction with Mixing and Displacement Ventilation," HVAC\&R Res., vol. 12 , no. 2 , pp. 295-311, 2006.
[9] "HVAC Design Manual for Hospitals and Clinics Second Edition,” Ashrae, 2013. 